\title{
Individual and Joint Actions of Selenate and Methylmercury on the Development and Survival of Insect Detritivore Megaselia scalaris (Diptera: Phoridae)
}

\author{
P. D. Jensen, L. R. Johnson, J. T. Trumble \\ Department of Entomology, University of California, 900 University Avenue, Riverside, California 92521, USA
}

Received: 4 May 2005/Accepted: 22 August 2005

\begin{abstract}
Despite the important roles played by insects in most ecosystems, surprisingly little is known about how anthropogenic pollutants or their mixtures interact to affect insect populations. The independent and joint actions of selenate and methylmercury on a ubiquitous insect detritivore, Megaselia scalaris (Loew), were determined in this study. Ovipositing females did not distinguish between untreated food sources and those contaminated with toxic concentrations of selenate, methylmercury, or both chemicals in combination. Even at the highest concentrations of pollutants, no negative effects were observed for the egg stage. However, larval survival was significantly decreased and development significantly prolonged by selenate and methylmercury individually at low or intermediate ecologically relevant treatment levels. Potentiation was strongly evident because mixtures containing concentrations as little as only $1 \%$ of the respective individual median lethal tolerances $\left(\mathrm{LC}_{50} \mathrm{~s}\right)$ caused significantly more mortality and delayed larval development than would be expected from the responses selenate and methylmercury elicit individually. However, survival and pupal development was not affected at any rate tested. Female fecundity was significantly decreased by methylmercury but not by selenate or mixture treatments. The relative toxicity to $M$. scalaris of each of the individual and joint treatments was selenate $\left(\mathrm{LC}_{50}=260 \mu \mathrm{g} / \mathrm{g}\right)<$ methylmercury $\left(\mathrm{LC}_{50}=22 \mu \mathrm{g} / \mathrm{g}\right)<$ the mixture at approximately $5 \%$ of the $\mathrm{LC}_{50}$ concentration of each of the components $(12 \mu \mathrm{g} / \mathrm{g}$ selenate plus $1.0 \mu \mathrm{g} / \mathrm{g}$ methylmercury). The increased mortality and delayed larval development within sites contaminated by selenate, methylmercury, or combination of the two have substantial implications for the ecology, population dynamics, and sustainability of $M$. scalaris populations. If these results can be extrapolated to other arthropod detritivores, ecosystem food-web function may be substantially affected.
\end{abstract}

As a class, insects dominate the world in which we live. More than $70 \%$ of all known species are insects, and

Correspondence to: P. D. Jensen; email: peter.jensen@email.ucr.edu insects occupy more habitats on the globe than any other organism in the animal kingdom (Resh and Cardé 2003). In many ecosystems, interactions involving insects and other arthropods provide the primary routes of energy flow, with insect biomass exceeding that of vertebrates (MacKensie and Kaster 2004). Insects serve not only as primary consumers and recyclers but also as secondary consumers and as food for higher trophic-level animals. Among the four or five trophic levels commonly present in many freshwater and terrestrial ecosystems, insects occupy the critical middle links (Thompson 1984). Despite these important roles, surprisingly little is known about how pollutants affect insects, possibly because of insects' diversity, ubiquitous distribution, and perceived lack of importance in most anthropomorphic activity (Trumble et al. 1998).

In an analysis of the literature that included all classes of organisms, Yang (1994) found that $>95 \%$ of the available toxicologic studies only examined the impact of individual chemicals. However, most organisms are likely to be challenged by complex mixtures in the environment rather than individual chemicals. Such mixtures can cause unexpected effects leading to potential interactions among toxicants that result in additive, antagonistic, or potentiation effects. Selenium (Se) and mercury $(\mathrm{Hg})$ were chosen for study in part because of the well documented antagonistic relationships between $\mathrm{Se}$ and $\mathrm{Hg}$ in fish (Ganther et al. 1972), birds (Welsh and Soares 1976), and mammals (Gailer et al. 2000). An additive relationship occurs when the toxicity of the mixture can be predicted from the dose-response curve for each component, assuming that each component acts independently and has a different mode of toxic action (Bliss 1939). An antagonistic relationship occurs when the toxicity of the mixture is less than expected based on the individual independent activity of each of the components. The opposite of antagonism is potentiation, i.e., the toxicity of the mixture is greater than expected. Within the general category of potentiation, there is the special case of synergism, where one of the components is nontoxic at the concentration used in the treatments (Raffa and Priester 1985).

Stark and Banks (2003) reported that $95 \%$ of the literature they reviewed used mortality and $\mathrm{LC}_{50}$ or concentration as a toxicologic end point. They suggested that because both lethal 
and sublethal effects of the toxicant contribute to the rate of population growth, measuring this parameter would result in more accurate assessments of the impact of toxicants. Similarly, Forbes and Calow (1999) found that demographic toxicologic studies of life-table responses provided more accurate assessments of toxicity than lethal concentration estimates. Although short-term acute tests allow for a quick assessment and comparability between species or toxicants, they are likely to underestimate the true effect of the toxicant. Indeed, Bechmann (1994) found that some toxicants could affect populations enough to cause extinction at concentrations well below the concentrations occurring on the traditional doseresponse curve. Thus, the longer tests, although certainly less efficient, may detect much more subtle effects and have more applicability in the field. Accordingly, we used chronicexposure toxicity testing in our experiments instead of 24- to 96-hour acute toxicity testing to determine relative toxicity values. In addition, we were interested in ecologically important responses (delayed development, egg mortality, ovipositional choice, larval mortality, and sex-linked effects), other than just adult mortality, that could have unapparent population-level effects from standard toxicologic analysis.

The alleviation of inorganic $\mathrm{Hg}$ toxicity by Se was reported as early as 1967, and the chemical mechanism of antagonism between sodium selenite and mercuric chloride has been described in mammalian tissue (Gailer et al. 2000). The mechanism consists of selenite being taken up by erythrocytes and reduced and expelled as selenide, which then reacts with albumin-bound mercuric $\mathrm{Hg}$ to form an $\mathrm{Hg}-\mathrm{Se}-\mathrm{S}$ species that binds to selenoprotein $\mathrm{P}$. The first report of the interaction between organic $\mathrm{Hg}$ (MeHg) and Se was by Ganther et al. (1972), and it clearly showed the alleviating affects of sodium selenite on $\mathrm{MeHg}$ induced toxicity in rats, although the mechanism is not known. In addition, it is unknown if a similar antagonistic relationship and mechanism occurs in arthropods. Insects reportedly respond in a similar fashion as vertebrates with respect to metal exposure by initiating synthesis of metal-induced metallothionen-like proteins (Hopkin 1989). However, this similarity between vertebrates and invertebrates may not readily extrapolate to toxicologic or ecologic effects. For the purposes of our study, Se and $\mathrm{Hg}$ were investigated not just for their noteworthy interactions in higher organisms but also for their frequent co-occurrence. In the 2002 303(d) list, the California Environmental Protection Agency (United States Environmental Protection Agency [USEPA] 2003) reported that $>600,000$ acres of land and waterways in California alone were contaminated by $\mathrm{Hg}$; another 500,000 acres of land and waterways were contaminated by $\mathrm{Se}$; and $>200,000$ acres of land and waterways were contaminated by a mixture of the two. $\mathrm{Hg}$ and $\mathrm{Se}$ are also listed together at 11 active Superfund sites in California (USEPA 2002). Outside of California, Se and $\mathrm{Hg}$ have been implicated in effects on biota at Maxwell National Wildlife Refuge in New Mexico (Custer 1993; Stillwater, Malheur, Seedskadee, Ouray, and Benton Lake National Wildlife Refuges (Henny et al. 2000); Minot Air Force Base in North Dakota (Dohner 1998); Helena Valley of Montana (USEPA 1987); and Wind River Indian Reservation in Wyoming (Clark and Sadler 1996). Thus, the importance of this particular combination of pollutants extends beyond just California. The primary objective of our study was therefore to examine the individual and joint toxicology of these two common anthropogenic pollutants, Se and $\mathrm{Hg}$, on the toxi- cologic responses and population dynamics of a ubiquitous insect detritivore that would encounter these materials in many different ecosystems.

\section{Materials and Methods}

\section{Test Organism}

Megaselia scalaris is a small phorid species of nearly ubiquitous distribution. Morphologic studies have shown well-developed pharyngeal ridges in M. scalaris larvae, which Dowding (1967) found were present only in cyclarrhaphous Diptera capable of feeding on a wide variety of host material. Larvae of this species have been reported developing on a wide variety of host material including decaying meat, insects, and a broad selection of decomposing plants (Robinson 1971). Thus, this species is a detritivore, and likely to feed on decaying plants or animals contaminated with many different pollutants, including $\mathrm{Se}$ and $\mathrm{Hg}$.

A laboratory colony of M. scalaris was established in 2001 from adult flies found feeding on an alfalfa-based diet (Mandeville et al. 1988) used for another insect species. The flies were reared at a constant $26^{\circ} \mathrm{C}$ and a photoperiod of 16 hours light to 8 hours darkness. For all tests, age of the eggs was synchronized by allowing groups of approximately 25 adult female insects from the colony to oviposit on Fisher's Drosophila Diet (Fisher Scientific, Pittsburgh, PA) in Petri dishes for 2 hours. The diet was prepared by rehydrating diet flakes with solutions containing sodium selenate (Sigma-Aldrich, Milwaukee, WI), methylmercury (II) chloride (Sigma-Aldrich), or both compounds at concentrations calculated by mass to produce the desired treatment levels. Diet concentrations of individual compounds were analyzed analytically (E. S. Babcock \& Sons, Riverside, CA) and were found to be within $5 \%$ of the desired treatment levels.

\section{Pollution Forms and Concentrations}

Se can be found in the environment at very high concentrations. In terrestrial systems, soils can be categorized as nonseleniferous, i.e., containing $<0.1$ to $4.3 \mu \mathrm{g} / \mathrm{g} \mathrm{Se}$, or seleniferous, i.e., commonly containing up to 80 but including as much as $4000 \mu \mathrm{g} / \mathrm{g}$ (McNeal and Balistrieri 1989). Vegetation in these systems can accumulate soluble forms of Se either from underground contamination plumes, by irrigation with contaminated water, or by growing near surface water that is contaminated (Frankenberger and Engberg 1998). To use ecologically relevant concentrations, the range of test concentrations for selenate in our experiments varied from 0 to $500 \mu \mathrm{g} / \mathrm{g}$.

In addition, Se has several different oxidation states including selenate $\left(\mathrm{Se}^{6+}\right)$, selenite $\left(\mathrm{Se}^{+4}\right)$, elemental $\mathrm{Se}\left(\mathrm{Se}^{0}\right)$, and selenides or organic forms of $\mathrm{Se}\left(\mathrm{Se}^{2+}\right)$, all of which can be found in the environment. However, in both natural and Se-contaminated waters, selenate and selenite are by far the most prevalent forms (Presser and Ohlendorf 1987), and selenate is often the most abundant, or secondmost abundant, form found in plants (Vickerman et al. 2004; Zayed et al. 1998). For this reason, the Se species chosen for all experiments was selenate.

Like Se, the chemical form of $\mathrm{Hg}$ determines its availability and toxicity to consumers. The major $\mathrm{Hg}$ species are elemental $\mathrm{Hg}\left(\mathrm{Hg}^{0}\right)$, inorganic $\mathrm{Hg}\left(\mathrm{Hg}^{2+}\right)$, and methylmercury $\left(\mathrm{CH}_{3} \mathrm{Hg}^{+}\right)$. Of all the forms studied, methylmercury was absorbed most quickly and retained the longest in animal tissue, and it often comprises up to $99 \%$ of the $\mathrm{Hg}$ in animal tissue (Selikoff 1971), reaching levels $>100 \mu \mathrm{g} / \mathrm{g}$ (Ramel and Magnusson 1969). Therefore, methylmercury was used in all trials at a concentration range of 0 to $40 \mu \mathrm{g} / \mathrm{g}$. 


\section{Oviposition Tests}

To measure the potential for ovipositional preference or avoidance of contaminated food, diets were prepared using 0 (control), 100, 200, 300,400 , and $500 \mu \mathrm{g} / \mathrm{g}$ sodium selenate and 0 (control), 15, and $30 \mu \mathrm{g} / \mathrm{g}$ methylmercury. Diets initially were dispensed into the bases of Petri dishes to a depth of $1.2 \mathrm{~cm}$. A no. 9 cork borer was then used to cut cylinders of diet $(1.2 \mathrm{~cm}$ deep $\times 1.2 \mathrm{~cm}$ wide $)$ from diets with each treatment concentration. These cylinders provided uniform shapes and quantities of diet for oviposition. The diet cylinders were arranged in groups of four in larger Petri dishes $(2.2 \mathrm{~cm}$ deep $\times 7.5 \mathrm{~cm}$ wide), with pairs of controls alternating with pairs of treatment cylinders containing a single concentration (after Trumble and Jensen 2004). Approximately 10 pairs of flies (both male and female) were introduced into each dish and allowed to oviposit for 2 days. Each concentration was replicated 10 times, thus requiring 1200 adult flies for the test. At the end of the oviposition period, the numbers of eggs on treatment and control cylinders were recorded for each dish. Ovipositional preference was analyzed using the Wilcoxon signed rank nonparametric procedure for paired comparisons (Statview 2001, SAS Institute, Cary, NC).

\section{Survival and Developmental Studies}

Contaminated Drosophila diet was prepared as described earlier in concentrations of $0,100,200,300,400$, and $500 \mu \mathrm{g} / \mathrm{g}$ sodium selenate; $0,15,25,30$, and $40 \mu \mathrm{g} / \mathrm{g}$ methylmercury chloride; and $0 \%$ to $25 \% \mathrm{LC}_{50}$ concentrations of selenate and methylmercury. Please note that in the interest of accuracy for any treatments below $\mathrm{LC}_{5}$, a percent of the $\mathrm{LC}_{50}$ concentration value was used rather than converting to values on the $\mathrm{LC} \log$-dose probit lines: Some of the concentrations tested were so low that describing an $\mathrm{LC}_{0.001}$ becomes nearly meaningless given the fiducial limits at such concentrations. These diets were dispensed into one side of $75-\mathrm{ml}$ clear plastic, divided Petri dishes. To pupariate, $M$. scalaris larvae either move to the surface or leave the food (Trumble and Pienkowski 1979). With this experimental procedure, the diet-free side of the dish provided a preferred site for pupariation, thus making counting easier. In all the following tests, each Petri dish received 20 eggs that were observed on treated diet throughout the life cycle.

Because of a known potential for insect eggs to absorb liquid from the surface of the diet (Chapman 1975) and thus possibly acquire Se or $\mathrm{Hg}$, an analysis was conducted to determine if numbers of noneclosing eggs differed with compound or treatment concentration. Eggs $<2$ hours old were transferred to the surface of Drosophila diets containing concentrations of (1) 0 to $500 \mu \mathrm{g} / \mathrm{g}$ sodium selenate or (2) 0 to $40 \mu \mathrm{g} / \mathrm{g}$ methylmercury or (3) $0.1 \%, 0.5 \%, 1 \%, 5 \%, 10 \%, 25 \%$ or $50 \%$ of $\mathrm{LC}_{50}$ concentrations of selenate plus methylmercury. The numbers of eggs eclosed after 12 hours were assessed for each of 8 replicates/concentration for each compound. These rates were compared with the controls for each test material using analysis of variance (ANOVA) (Statview 2001).

For the survival and developmental studies, 8 replicate Petri dishes containing 20 eggs each were tested for each concentration, yielding a total of 960 eggs. The potential confounding effects of any slow eclosion or egg mortality caused by handling were eliminated by removing any eggs that had not hatched within 12 hours (average $<10 \%$ ). The dishes were maintained at $26^{\circ} \mathrm{C}$ with a photoperiod of 16 hours light to 8 hours dark. The dishes were examined daily, and numbers of pupae were recorded. The date of adult emergence and the sex of emerging adults were also recorded daily for each dish for 35 days or until all individuals had completed development to the adult stage. This procedure allowed documentation of the larval development period, the duration of pupal development, the total (larval and pupal) developmental time, and the number of individuals surviving to the adult stage. All development and survival data were analyzed using ANOVA (Statview 2001). Percentage data were transformed with an arcsine transformation before analysis to confer normality and back-transformed for presentation. Data were not used from any experiments in which control mortality exceeded $15 \%$, the accepted critical value used in insect bioassays (Robertson and Preisler 1992), and Abbott's formula was used to correct for the control mortality that occurred (Tattersfield and Morris 1924). As appropriate, ANOVA was followed by a post hoc analysis with Tukey's Honestly Significant Difference to determine developmental or survival differences between individual concentrations within selenate, methylmercury, or mixture treatments.

\section{Relative Toxicity of Compounds and Mixtures}

To measure the $\mathrm{LC}_{50}$ for each of the compounds, diets were prepared using 0 (control), 100, 200, 300, 400, and $500 \mu \mathrm{g} / \mathrm{g}$ sodium selenate and 0 (control), 15, 25, 30, and $40 \mu \mathrm{g} / \mathrm{g}$ methylmercury. We then mixed selenate and methylmercury in decreasing percentages of their respective $\mathrm{LC}_{50}$ concentrations to determine the relative toxicity of the mixtures.

To determine whether the two compounds caused an antagonistic, additive, or potentiated toxicologic reaction in M. scalaris, lifetime mortality rates were assessed for a mixture of selenate and methylmercury at their respective $\mathrm{LC}_{25}$ concentrations. A mixture of $\mathrm{LC}_{25}$ concentrations would be expected to produce slightly less than an $\mathrm{LC}_{50}$ response if the relationship is additive, much less than $\mathrm{LC}_{50}$ if the relationship is antagonistic, and much greater than $\mathrm{LC}_{50}$ if potentiation occurs. To evaluate the interactions at lower concentrations, we employed a test for synergism (Tabashnik 1992) that includes a calculation of the expected $\mathrm{LC}_{50}$ of the mixture:

$$
\mathrm{LC}_{50(\text { mix })}=\left[r_{a} / \mathrm{LC}_{50(a)}+r_{b} / \mathrm{LC}_{50(b)}\right]^{-1},
$$

where $r$ is the relative proportion of $a\left(r_{a}\right)$ and $b\left(r_{b}\right)$ in the mixture. We then compared the expected $\mathrm{LC}_{50}$ of the mixture with the observed mixture $\mathrm{LC}_{50}$ and the $95 \%$ confidence limits of the observed $\mathrm{LC}_{50}$ to test for potentiation. Potentiation is considered to be occurring if the observed $\mathrm{LC}_{50}$ is greater than the expected $\mathrm{LC}_{50}$. Because high mortality was observed in mixtures at $\mathrm{LC}_{25}$ concentrations, the concentrations were decreased to mixtures of approximately $\mathrm{LC}_{10}$ and $\mathrm{LC}_{5}$ levels.

Diets containing selenate, methylmercury, or a mixture were dispensed into one side of 75-ml clear plastic, divided Petri dishes as described previously. Again, each Petri dish received 20 eggs. Any eggs that had not hatched within 12 hours (average $<10 \%$ ) were removed to eliminate any potential confounding effect of egg mortality caused by handling. Eight replicate Petri dishes were tested for each concentration of each compound, yielding a total of 960 eggs for sodium selenate, 800 eggs for methylmercury, and 1120 eggs for mixture trials, including $\mathrm{LC}_{25}$ concentrations, $\mathrm{LC}_{10}$ concentrations, and controls $(0 \mu \mathrm{g} / \mathrm{g})$. The dishes were examined daily, and pupariation or adult emergence was recorded. The $\mathrm{LC}_{50}$ values were calculated using probit analysis (Minitab Statistical Software 2000, Minitab Inc., State College, PA).

\section{Fecundity Experiments}

Survivors from the relative toxicity experiments were used to examine any effects of the treatments on the fecundity of the female M. scalaris. Emerging male and female individuals were paired in 30- 


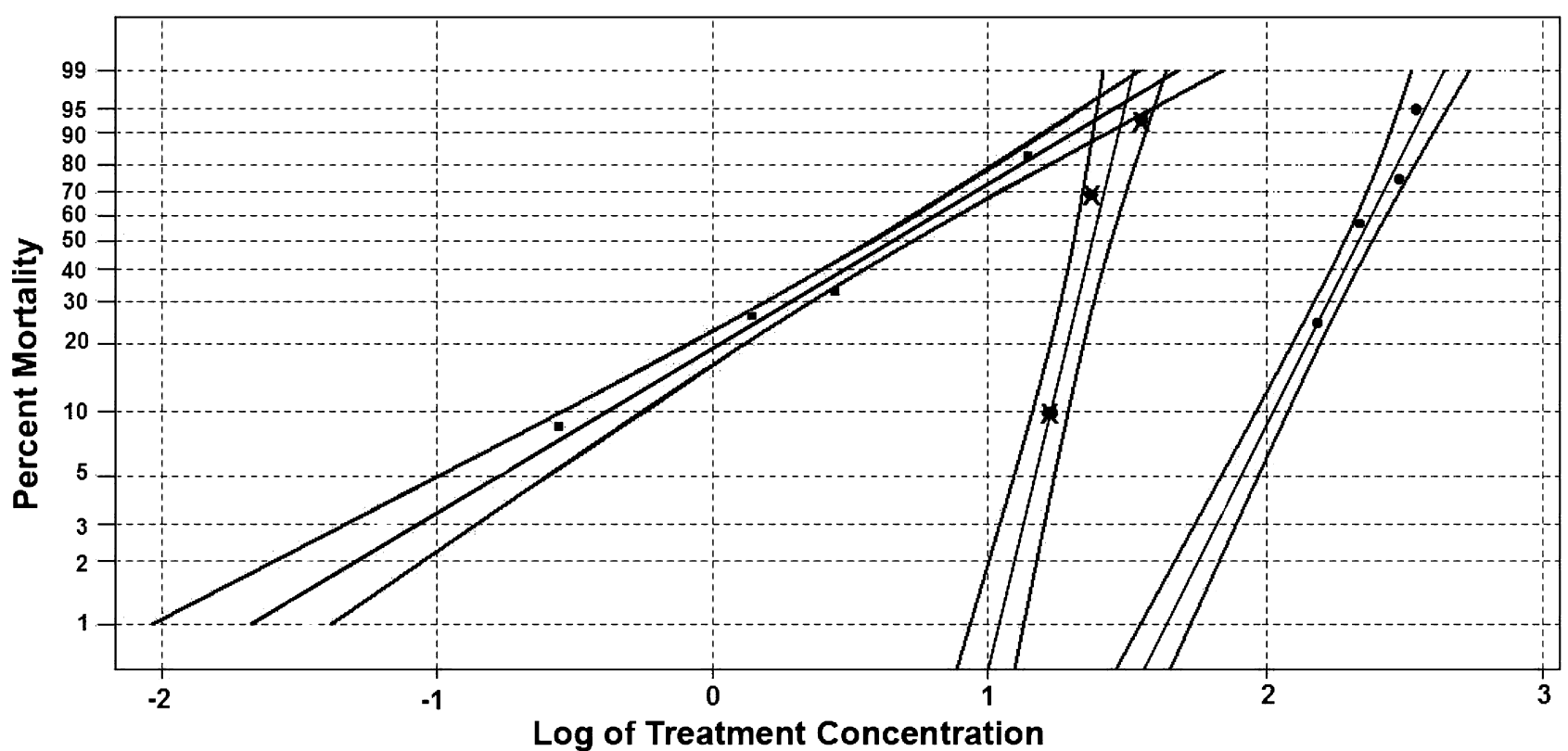

Fig. 1. Probit model dose-response curves for selenate (right), methylmercury (center), and a mixture of approximately 13:1 of selenate and methylmercury (left).

$\mathrm{ml}$ plastic cups containing approximately $10 \mathrm{ml}$ untreated diet. Ten pairs of male and female individuals were examined for each treatment. After 10 days, the diet was diluted and filtered with a $250-\mu \mathrm{m}$ screen, and all larvae were counted. The number of viable eggs per female insect from each treatment was analyzed using ANOVA (Statview 2001).

\section{Results}

\section{Oviposition}

There were no significant differences in oviposition preference by female $M$. scalaris between the controls and the highest levels for each of the selenate or methylmercury concentrations. Selenate was tested at a maximum rate of $500 \mu \mathrm{g} / \mathrm{g}$ (Wilcoxon signed rank, $p \geq 0.441$ ); methylmercury was tested at a maximum rate of $30 \mu \mathrm{g} / \mathrm{g},(p \geq 0.879)$.

\section{Survival and Development Studies}

The survival of $M$. scalaris eggs was not decreased when exposed to any selenate treatments $\left(F_{5,41}=1.04, p=0.410\right)$, methylmercury treatments $\left(F_{5,41}=1.41, p=0.240\right)$, or any mixture of selenate and methylmercury treatments tested $\left(F_{4,35}=1.20, p=0.330\right)$. Thus, either the eggs did not absorb any of the pollutants, or the materials did not have a negative effect on the eggs.

Larval survival was significantly decreased by selenate $\left(F_{5,41}=63.96, p=0.001\right)$ as listed in Table 2. Selenate significantly decreased survival by $27 \%$ at the lowest concentration tested $(100 \mu \mathrm{g} / \mathrm{g})$ and by $79 \%$ in the highest treatment $(500 \mu \mathrm{g} / \mathrm{g})$. The lowest concentration of methylmercury that had a significant effect $\left(F_{4,35}=10.43, p=0.001\right)$ was $30 \mu \mathrm{g} / \mathrm{g}$, and this concentration decreased larval survival by $81 \%$ (Table 2). The selenate-methylmercury mixture also significantly decreased larval survival compared with controls $\left(F_{4,35}=11.36, p=0.001\right)$. The mixture containing $1 \%$ of $\mathrm{LC}_{50}$ concentrations $\left(2.6 \mu \mathrm{g} / \mathrm{g} \mathrm{Se}{ }^{6+}, 0.2 \mu \mathrm{g} / \mathrm{g} \mathrm{MeHg}\right)$ caused a significant increase in mortality $(32 \%)$ compared with controls, which was the lowest rate that showed significant activity (Table 2). At the rate of $10 \%$ of the $\mathrm{LC}_{50}$ concentrations $\left(26 \mu \mathrm{g} / \mathrm{g} \mathrm{Se}^{6+}, 2.2 \mu \mathrm{g} / \mathrm{g} \mathrm{MeHg}\right)$, the mixture caused $100 \%$ mortality. Interestingly, despite the mortality observed in the larval stage, the survival of puparia was not affected in any of the treatments of selenate $\left(F_{5,41}=0.02, \quad p=0.999\right)$, methylmercury $\left(F_{4,35}=2.15, p=0.096\right)$, or their mixtures $\left(F_{4,35}=0.07, p=0.990\right)$.

The total mortality caused over the life cycle of $M$. scalaris was most influenced by the larval mortality. Overall, selenate significantly decreased survival $\left(F_{5,41}=69.84, p=0.001\right)$ by $28 \%$ at the lowest concentration tested $(100 \mu \mathrm{g} / \mathrm{g})$ and by $79 \%$ at the highest treatment $(500 \mu \mathrm{g} / \mathrm{g})$. Methylmercury caused a significant decrease in overall survival $\left(F_{4,35}=16.63\right.$, $p=0.001$ ) by $67 \%$ at $25 \mu \mathrm{g} / \mathrm{g}$. Finally, overall survival was significantly decreased-by $68 \%-\left(F_{4,31}=8.15, p=0.001\right)$ by the treatment containing $5 \%$ of the $\mathrm{LC}_{50}$ mixture compared with controls.

Significant delays in larval developmental time occurred at concentrations as low as $100 \mu \mathrm{g} / \mathrm{g}$ for selenate $\left(F_{5,41}=37.60\right.$, $p=0.001)$. However, selenate did not cause any significant differences in the number of days required to complete pupariation $\left(F_{5,41}=1.36, p=0.259\right)$. Thus, once pupariation occurs, development to the adult stage proceeded in a consistent time period regardless of the concentration tested. Methylmercury also caused significant delays in developmental time at concentrations lower than those affecting survival of the larvae. Although larval mortality was not 
Table 1. Mixture component concentrations with corresponding observed percent mortality and calculated expected mortality

\begin{tabular}{|c|c|c|c|c|c|}
\hline Treatment & $\begin{array}{l}\mathrm{Se}^{(6+)} \text { concentration } \\
(\mu \mathrm{g} / \mathrm{g})\end{array}$ & $\begin{array}{l}\mathrm{MeHg} \text { concentration } \\
(\mu \mathrm{g} / \mathrm{g})\end{array}$ & $\begin{array}{l}\text { Expected } \mathrm{LC}_{50} \\
(\mu \mathrm{g} / \mathrm{g})\end{array}$ & $\begin{array}{l}\text { Expected mortality } \\
(\%)\end{array}$ & $\begin{array}{l}\text { Observed mortality } \\
(\%)\end{array}$ \\
\hline $\mathrm{LC}_{50} \mathrm{Se}^{(6+)}$ & 260 & & & 50 & $50 \pm 0.56$ \\
\hline $\mathrm{LC}_{50} \mathrm{MeHg}$ & & 22 & & 50 & $50 \pm 1.1$ \\
\hline $\mathrm{LC}_{25} \operatorname{mix}$ & 72 & 12 & 102 & 50 & 100 \\
\hline $\mathrm{LC}_{10} \operatorname{mix}$ & 29 & 10 & 69 & 20 & 100 \\
\hline $\mathrm{LC}_{5} \operatorname{mix}$ & 14 & 9 & 54 & 10 & 100 \\
\hline $50 \%$ of $\mathrm{LC}_{50} \operatorname{mix}$ & 127 & 11 & 24 & 50 & 100 \\
\hline $25 \%$ of $\mathrm{LC}_{50} \mathrm{mix}$ & 65 & 5.5 & 24 & 25 & 100 \\
\hline $10 \%$ of $\mathrm{LC}_{50} \mathrm{mix}$ & 26 & 2.2 & 24 & 10 & 100 \\
\hline $5 \%$ of $\mathrm{LC}_{50} \mathrm{mix}$ & 13 & 1.1 & 24 & 5 & $68 \pm 0.68$ \\
\hline $1 \%$ of $\mathrm{LC}_{50}$ mix & 2.6 & 0.2 & 24 & 1 & $28 \pm 2.3$ \\
\hline $0.5 \%$ of $\mathrm{LC}_{50} \operatorname{mix}$ & 1.3 & 0.1 & 24 & 0.5 & $17 \pm 2.5$ \\
\hline $0.1 \%$ of $\mathrm{LC}_{50} \operatorname{mix}$ & 0.26 & 0.02 & 24 & 0.1 & $7 \pm 1.4$ \\
\hline
\end{tabular}

$\mathrm{LC}_{50}=$ Median lethal concentration.

significantly different from controls up to $25 \mu \mathrm{g} / \mathrm{g}$, larval developmental time was significantly different from controls at concentrations as low as $10 \mu \mathrm{g} / \mathrm{g}\left(F_{5,35}=6.324, p=0.001\right)$. Interestingly, the number of days required to complete pupariation was also significantly different from controls as the methylmercury concentration increased $\left(F_{4,26}=9.72\right.$, $p=0.001)$. This result, however, may be an artifact of the low survival rates of the puparia in the treatments with higher concentrations because the mean pupariation times and treatment concentrations are inversely related.

The mixtures of selenate and methylmercury also delayed larval development. Significant differences between the control and treatment groups occurred at the $1 \%$ of $\mathrm{LC}_{50}$ level $\left(\mathrm{Se}^{6+}\right.$ at $2.6 \mu \mathrm{g} / \mathrm{g}$ and $\mathrm{MeHg}$ at $0.2 \mu \mathrm{g} / \mathrm{g} ; \quad F_{4,35}=5.05$, $p=0.003)$ and increased with higher concentrations. There were no significant differences in pupariation time between the control and treatment groups. We did not observe any significant sex-linked delays in development time or sex-linked differences in survival of $M$. scalaris exposed to selenate, methylmercury, or mixtures of the two components.

\section{Relative Toxicity of Compounds and Mixtures}

The $\mathrm{LC}_{50}$ s for selenate, methylmercury, or the mixture of the two were determined for $M$. scalaris. The $\mathrm{LC}_{50}$ of selenate was $260 \mu \mathrm{g} / \mathrm{g}$ and that of methylmercury was $22 \mu \mathrm{g} / \mathrm{g}$. The $\mathrm{LC}_{50}$ for the mixture occurred just below $5 \%$ of the $\mathrm{LC}_{50}$ concentration of each of the components or at approximately $12 \mu \mathrm{g} / \mathrm{g}$ of Se $\mathrm{Se}^{6+}$ and $1.0 \mu \mathrm{g} / \mathrm{g}$ of $\mathrm{MeHg}$. The log-dose probit models for selenate, methylmercury, and the mixture are shown in Figure 1. Please note that treatments causing $0 \%$ or $100 \%$ mortality are not included in the probit model. In addition, although the probit models for the mixture and methylmercury intersect in Figure 1, it should be noted that this occurs at a methylmercury dose of approximately $42 \mu \mathrm{g} / \mathrm{g}$ and a mixture dose consisting of approximately $39 \mu \mathrm{g} / \mathrm{g}$ selenate and only 3.3 $\mu \mathrm{g} / \mathrm{g}$ methylmercury.

\section{Fecundity}

Selenate did not cause any significant differences in the fecundity of female individuals with any of the treatments versus controls. Conversely, methylmercury caused a significant decrease in the number of viable eggs produced by each female compared with the control insects $\left(F_{3,36}=30.755\right.$, $p=0.001)$ at the lowest concentration tested $(5 \mu \mathrm{g} / \mathrm{g})$. The average number of viable eggs per female in the methylmercury treatments are listed in Table 2. Surprisingly, the mixture of selenate and methylmercury did not cause any significant differences in the fecundity of the female individuals that developed on the treatments compared with the controls.

\section{Discussion}

To address the important issue of exposure, the ability of female $M$. scalaris to avoid a food source containing selenate or methylmercury was tested. When choosing an oviposition site, female insects did not distinguish between untreated control substrate and even the substrates with the highest treatment concentrations of selenate or methylmercury. Although this oviposition experiment occurred during 2 days, food sources or oviposition sites exposed to bacterial degradation for a longer period of time might produce volatile $\mathrm{Se}$ or $\mathrm{Hg}$ species that could potentially alter the ovipositional preference of female M. scalaris. A similar inability to distinguish between contaminated, unsuitable larval food sources and food sources acceptable to larvae was observed for the pollutant hexavalent chromium (Trumble and Jensen 2004). Because the eggs are immobile, and the larvae are not capable of substantial movement, offspring are restricted to the food source chosen by the female individuals at the time of oviposition. This contrasts with herbivores that have shown sensitivity to Se in their diet and can behaviorally modify the amount of Se consumed in choice-tests (Vickerman and Trumble 1999; Vickerman et al. 2002). Thus, the ecologic implications of Se and methylmercury contamination for species diversity within contaminated sites are substantial.

Although the egg survival rates were not affected by selenate or methylmercury, the larvae hatching on a contaminated food source would experience delayed development and increased mortality dependent on the concentration of Se and/or methylmercury in the food source. The levels found to affect development and mortality, although increased, were ecologically relevant in some areas as previously described. These 


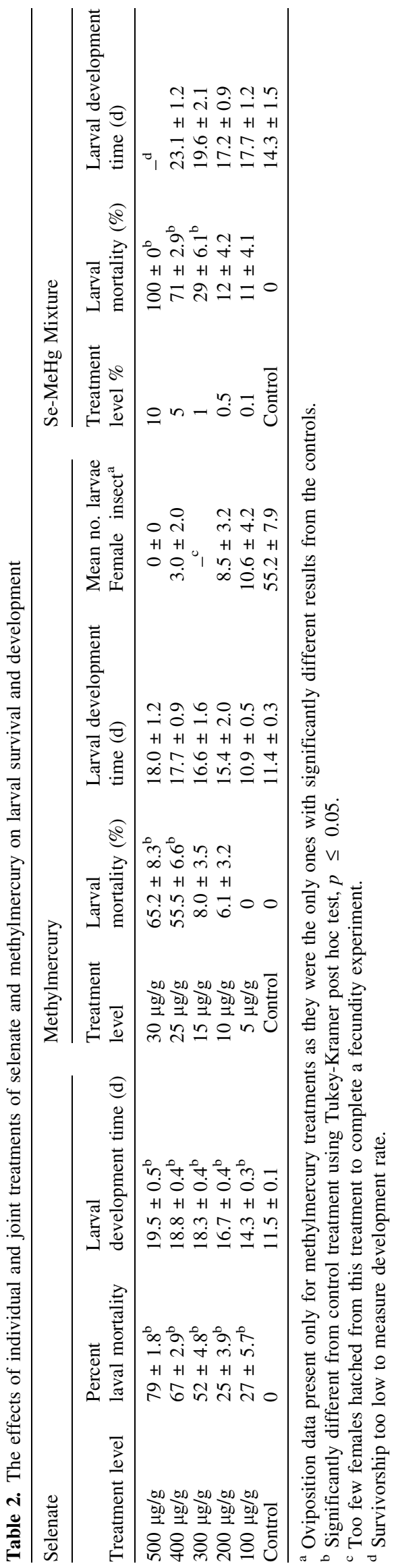

results were not unexpected because studies using insect herbivores (Trumble et al. 1998; Vickerman and Trumble 1999), or insect predators (Vickerman and Trumble 2003) exposed to Se also found decreased survivorship and/or delayed development. In addition, acridid grasshopper nymphs (Acrotylus patruelis) developing on $\mathrm{Hg}$-contaminated diet had prolonged nymphal stage duration (40\% to $100 \%$ longer) and $70 \%$ mortality compared with control insects that received no $\mathrm{Hg}$ (Heliovaara and Vaisanen 1993). Aphids reared on methylmercury-contaminated tomato plants had longer developmental times than those reared on control plants (Haney and Lipsey 1973). M. scalaris was similarly affected: Delays in larval development (up to an average of 8 days for selenate, 7 days for methylmercury, and 9 days for mixtures) would have serious implications for the survival of a population exposed to these levels of contamination. Additional developmental time not only increases exposure to predators and parasites but would likely impact population fitness in many ecosystems because the availability of food sources for the larvae are generally temporary (Trumble and Pienkowski 1979), and extending larval developmental times could exceed the duration of the suitability of the food supply. In addition to prolonged development, larval mortality was significantly increased compared with controls in the treatment containing $100 \mu \mathrm{g} / \mathrm{g}$ selenate, the treatment containing $25 \mu \mathrm{g} / \mathrm{g}$ methylmercury, and the treatment containing $1 \%$ of $\mathrm{LC}_{50}$ components mixture $\left(2.6 \mu \mathrm{g} / \mathrm{g} \mathrm{Se}^{6+}\right.$ and $\left.0.2 \mu \mathrm{g} / \mathrm{g} \mathrm{MeHg}\right)$. Thus, the increased developmental times and mortality within sites contaminated by Se, methylmercury, or their combination have substantial implications for the population dynamics and sustainability of $M$. scalaris populations.

The general lack of effects of the contaminants on the pupal stage of M. scalaris is interesting. Heliovaara and Vaisanen (1993) noted that the pupal stage is generally well protected against the effect of pollutants, but prolongation of pupal development has been reported. The only significant difference observed in the duration of the pupal stage was a decrease in the methylmercury treatments. However, as mentioned earlier, this decrease may have been an artifact of the low survival rates of the puparia in the treatments with higher concentrations because the mean pupariation times and treatment concentrations were inversely related.

Unlike a previous study (Jensen et al. 2005), no sex-linked differences in development or mortality were observed for Se. The differences in Jensen et al. 2005 were likely related to the different forms of Se tested: They reported that female insects emerged from pupation significantly later than male insects for treatments containing organic forms of Se (selenoL-methionine and selenocysteine) rather than for the selenate examined in the current study.

The relative toxicities of each of the treatments, i.e., selenate, methylmercury, and their mixture, were very different. The methylmercury was much more toxic than the selenate, and the mixture of the two compounds was substantially more toxic to the larvae of M. scalaris than either the selenate or methylmercury alone. Mixtures of approximately $\mathrm{LC}_{25}+$ $\mathrm{LC}_{25}, \mathrm{LC}_{10}+\mathrm{LC}_{10}$, or $\mathrm{LC}_{5}+\mathrm{LC}_{5}$ concentrations of the two compounds were $100 \%$ fatal to the larvae. Although it would be interesting to decrease the concentrations to much lower levels to determine a dose-response curve for the mixture that is directly related to the dose-response curves of the compo- 
nents, the extrapolation to such low levels using the probit model renders them meaningless. However, it would be inaccurate to arbitrarily choose a mixture ratio to test when the dose-response curves of each single compound are so different. Therefore, we tested fractions of the $\mathrm{LC}_{50}$ concentration from $50 \%$ down to $0.1 \%$ (Table 1 ). The mortality was $100 \%$ until the mixture treatment decreased $<10 \%$ of the $\mathrm{LC}_{50}$ of each component. In fact, the $\mathrm{LC}_{50}$ for the mixture contained levels of each component that were just $<5 \%$ of their individual $\mathrm{LC}_{50}$ concentrations. According to Tabashnik's (1992) criteria, this is a clear case of potentiation. In fact, because methylmercury was not toxic in our study to $M$. scalaris at this low concentration $(1.1 \mu \mathrm{g} / \mathrm{g})$, this result could also be classified as a case of synergism. Please note that in Table 1, the expected $\mathrm{LC}_{50}$ of the $\mathrm{Se}-\mathrm{MeHg}$ mixture varies with $\mathrm{LC}_{25}, \mathrm{LC}_{10}$, and $\mathrm{LC}_{5}$ extrapolations based on $M$. scalaris responses to the single compounds because the ratio of the components in the mixture changes due to different slopes on the probit models for selenate and methylmercury. The expected $\mathrm{LC}_{50}$ did not change for the percentage mixtures because the ratio of the components remained constant.

Finally, the fecundity of the female individuals exposed to each of the treatments differed by compound. Although selenate and the mixtures did not have significant effects on fecundity, methylmercury significantly decreased the fecundity of female insects reared on the lowest concentration we tested $(5 \mu \mathrm{g} / \mathrm{g})$, with an average of $45 \mathrm{eggs}$ fewer than those reared on the control diet. This is not unprecedented. Heliovaara et al. (1990) found that female sawfly Neodiprion sertifer reared on metal-polluted needles oviposited an average of 10 eggs less than those reared on unpolluted needles (69 vs. 79 eggs). In addition, aphids reared on tomato plants contaminated with methylmercury exhibited significantly decreased fecundity (Haney and Lipsey 1973). In our study, the methylmercury alone decreased fecundity, but methylmercury in combination with Se did not.

To our knowledge, this is the first study to examine the joint effects of selenate and methylmercury on any species of arthropod. Interestingly, the relationship between selenate and methylmercury was not antagonistic as would be predicted from previous studies on fish, birds, and mammals. Not only was the relationship not antagonistic, the two compounds had a significant potentiation effect, causing much greater toxicity that we would have expected from their individual toxicities. We speculate that the reason for the potentiation rather than antagonism may be because of the lack of Sedependent glutathione peroxidase in some insects (Simmons et al. 1989), which acts as an important component of the antioxidant system in mammals. This potentiation that we observed between selenate and methylmercury was also evident in the decreased developmental rate of $M$. scalaris. A similar situation in the field would have strongly negative consequences for a population of $M$. scalaris, both through direct mortality as well as prolonging development on resources that are often transiently suitable. In addition, a decrease in the $M$. scalaris population could have additional effects on ecosystem stability not only through the loss of an important detritivore but through the loss of an abundant prey species. If these results can be extrapolated to other arthropod detritivores, ecosystem food-web function may be substantially affected.
Acknowledgments. We appreciate the identification of M. scalaris by B. Brown, Natural History Museum of Los Angeles County. We thank W. Carson, G. Kund, D. Liu, M. Sorensen, T. Paine, W. Walton, and D. Schlenk for their critical review of this manuscript. Support for this study was provided through the EPA STAR program, Project No. RD-83084101, and through the National Research Initiative of the United States Department of Agriculture Cooperative State Research, Education and Extension Service, Grant No. 2003-35101-13630.

\section{References}

Bechmann RK (1994) Use of life tables and $\mathrm{LC}_{50}$ tests to evaluate chronic and acute toxicity effects of copper on the marine copepod Tisbe furcata (Baird). Environ Toxicol Chem 13:1509-1517

Bliss CI (1939) The toxicity of poisons applied jointly. Ann Appl Biol 26:585-615

Chapman RF (1975) The insects: Structure and function. Elsevier, New York, NY

Dowding VM (1967) The function and ecological significance of the pharyngeal ridges occurring in the larvae of some cyclorrhaphous Diptera. Parasitology 57:371-388

Forbes VE, Calow P (1999) Is the per capita rate of increase a good measure of population-level effects in ecotoxicology? Environ Toxicol Chem 18:1544-1556

Gailer J, George GN, Pickering IJ, Madden S, Prince RC, Yu EY, et al. (2000) Structural basis of the antagonism between inorganic mercury and selenium in mammals. Chem Res Toxicol 13:11351142

Ganther HE, Goudie C, Sunde ML, Kopecky MJ, Wagner R, SanHwang OH, et al. (1972) Selenium relation to decreased toxicity of methylmercury added to diets containing tuna. Science 72:1122-1124

Haney A, Lipsey RL (1973) Accumulation and effects of methyl mercury hydroxide in a terrestrial food chain under laboratory conditions. Environ Pollut 5:305-316

Heliovaara K, Vaisanen R (1993) Insects and pollution. CRC, Ann Arbor, MI

Heliovaara K, Vaisanen R, Varama M (1990) Fecundity and egg viability in relation to female body size in Neodiprion sertifer (Hymenoptera: Diprionidae). Holarctic Ecol 13:166-172

Hopkin SP (1989) Ecophysiology of metals in terrestrial invertebrates. Elsevier Applied Science, New York, NY

Jensen PD, Arias M, Trumble JT (2005) Toxicological and developmental responses of a terrestrial insect detritivore, Megaselia scalaris (Loew) to four selenium species. Ecotoxicology 14:311-320

MacKensie RA, Kaster JL (2004) Temporal and spatial patterns of insect emergence from a Lake Michigan coastal wetland. Wetlands 24:688-700

Mandeville JD, Mullens BA, Meyer JA (1988) Rearing and host age suitability of Fannia canicularis (L.) (Diptera: Muscidae) for parasitization by Muscidifurax zaraptor Kogan and Legner (Hymenoptera: Pteromalidae). Can Entomol 120:153-159

McNeal JM, Balistrieri LS (1989) Geochemistry and occurrence of selenium: An overview. In: Jacobs LW (ed) Soil Science Society Special of America Publication Number 23. American Society of Agronomy, Inc. and Soil Science Society of America, Inc., Madison, WI, pp. 1-14

Presser TS, Ohlendorf HM (1987) Biogeochemical cycling of selenium in the San Joaquin Valley, California, USA. Environ Manage 11:805-821

Raffa KF, Priester TM (1985) Synergists as research tools and control agents in agriculture. J Agric Entomol 2:27-45

Ramel C, Magnusson J (1969) Genetic effects of organic mercury compounds. Chromosome segregation in Drosophila melanogaster. Hereditas 61:231-354 
Rayed A, Lytle CM, Terry N (1998) Accumulation and volatization of different chemical species of selenium by plants. Planta 206:284292

Robertson JL, Preisler HK (1992) Pesticide bioassays with arthropods. CRC, Boca Raton, FL

Robinson WH (1971) Old and new biologies of Megaselia species (Dipt. Phoridae). Studia Entomologica 14:321-348

Selikoff IJ (1971) Hazards of mercury. Environ Res 4:1-69

Simmons TW, Jamall IS, Lockshin RA (1989) Selenium-independent glutathione peroxidase activity associated with glutathione stransferase from the housefly, Musca domestica. Comp Biochem Physiol 94B:323-327

Stark JD, Banks JE (2003) Population-level effects of pesticides and other toxicants on arthropods. Annu Rev Entomol 48:505-519

Tabashnik BE (1992) Evaluation of synergism among Bacillus thuringiensis toxins. Appl Environ Microbiol 58:3343-3346

Tattersfield F, Morris HM (1924) Spraying apparatus. Bull Entomol Res 14:223

Thompson JN (1984) Insect diversity and trophic structure of communities. In: Huffaker CB, Rabb RL, (eds) Ecological entomology, Wiley, New York, NY,

Trumble JT, Jensen PD (2004) Ovipositional response, developmental effects and toxicity of hexavalent chromium to Megaselia scalaris, a terrestrial detritivore. Arch Environ Contam Toxicol 46:372-376
Trumble JT, Kund GS, White KK (1998) Influence of form and quantity of selenium on the development and survival of an insect herbivore. Environ Poll 101:175-182

Trumble JT, Pienkowski RL (1979) Development and survival of Megaselia scalaris (Diptera: Phoridae) at selected temperatures and photoperiods. Proc Entomol Soc Wash 81:207-210

Vickerman DB, Trumble JT, George GN, Pickering IJ, Nichol H (2004) Selenium biotransformations in an insect ecosystem: Effects of insects on phytoremediation. Environ Sci Technol 38:3581-3586

Vickerman DB, Trumble JT (1999) Feeding preferences of Spodoptera exigua in response to form and concentration of selenium. Arch Insect Biochem Physiol 42:64-73

Vickerman DB, Trumble JT (2003) Biotransfer of selenium: Effects on an insect predator, Podisus maculiventris. Ecotoxicology 12:497-504

Vickerman DB, Young JK, Trumble JT (2002) Effect of seleniumtreated alfalfa on development, survival, feeding and oviposition preferences of Spodoptera exigua (Lepidoptera: Noctuidae). Environ Entomol 31:953-959

Welsh SO, Soares JH (1976) Protective effects of vitamin-E and selenium against methylmercury toxicity in Japanese quail. Nutr Rep Int 13:43-51

Yang RSH (1994) Toxicology of chemical mixtures. Academic, New York, NY 